\title{
DEMOCRATIC MECHANISMS: DOUBLE MAJORITY RULES AND FLEXIBLE AGENDA COSTS
}

\author{
HANS GERSBACH
}

CESIFo Working PaPer No. 749

CAtegory 2: Public ChOICE

JULY 2002 


\title{
DEMOCRATIC MeChanisms: Double MAJORITY RULES AND FLEXIBLE AGENDA Costs
}

\begin{abstract}
We introduce democratic mechanisms where individual utilities are not observable by other people at the legislative stage. We show that the combination of three rules can yield e \pm cient provision of public projects: first, flexible and double majority rules where the size of the majority depends on the proposal and taxed and non-taxed individuals need to support the proposal; second, flexible agenda costs where the agenda-setter has to pay a certain amount of money if his proposal does not generate enough supporting votes; third, a ban on subsidies. We also illustrate that higher dimensional uncertainty about project parameters can make it easier to achieve first-best allocations and that universal equal treatment with regard to taxation is undesirable.
\end{abstract}

JEL Classification: D62, D72, H40.

Keywords: democratic constitutions, unobservable utilities, double majority rules, flexible agenda cost rules.

\author{
Hans Gersbach \\ Alfred-Weber-Institut \\ University of Heidelberg \\ Grabengasse 14 \\ 69117 Heidelberg \\ germany \\ gersbach@uni-hd.de
}

I would like to thank Peter Bernholz, Ulrich Erlenmaier, Volker Hahn, Hans Haller, Martin Hellwig, Benny Moldovanu, Herve Moulin, Manfred Nermuth, Anna Rubinchik-Pessach, Klaus Schmidt, Urs Schweizer, seminar participants in Gerzensee, Heidelberg, Irvine and Munich and participants at the International Meeting of the Society for Social Choice and Welfare 2000 in Alicante and at the annual Meeting of the European Economic Association 2001 for valuable comments and suggestions. 


\section{Introduction}

Adopting the incomplete contract approach to social contracts from Aghion and Bolton (1998), Erlenmaier and Gersbach (1999) have illustrated that increasingly sophisticated treatment, agenda and decision rules yield an efficient provision of public projects in democracies, provided that agents observe who benefits and loses from public projects when the agenda is set. While this assumption is reasonable for a number of examples, such as the construction of roads, labor market reforms or the scale-down of the defense industry, it is not plausible in all circumstances. Consider, for instance, the increase of safety through a rise in the number of police officers in the street. There is no way that other citizens can observe who feels safer and who does not.

In this paper we therefore discuss how democracies can be improved by constitutional principles when no complete social contracts can be written and individual utilities are not observable by other people during legislation. We employ a mechanism design approach involving a set of constitutional principles. The constitutional principles assumed in this paper must obey liberal democracy's fundamental principles of equal voting and agenda rights. Moreover, the constitutional principles must not require more messages or information from citizens than proposals or voting, including the possibility of non-participation. All these constraints are called the liberal-democracy constraint. Accordingly, democratic mechanisms are understood as the liberal-democracy constraint on the set of all available constitutions or mechanisms. ${ }^{1}$

When an agenda-setter cannot observe who benefits and who loses, the problem he faces is that he cannot impose taxes on the beneficiaries of a project only. Moreover, agenda-setters do not know how high the proportion of project-winners actually is. Nevertheless, we show in this paper that democratic constitutions can achieve first-best allocations in a variety of circumstances. The first novel element in this paper is the double majority rule. Double majority rules require the adoption of proposals among both the set of taxed and among the set of non-taxed individuals. The double majority rules act as a constraint on the taxes agenda-setters will levy on other individuals. They can be combined with flexible majority rules where the size of the majority depends on the proposal, e.g. on the share of taxed individuals.

\footnotetext{
${ }^{1}$ Without the liberal-democracy constraint there are always mechanisms for implementing socially efficient public project provisions in our context (see e.g. Moore 1992, Moulin 1996).
} 
The second novel element of the constitutions proposed is that agenda costs are made dependent on whether a particular share of votes supporting an agenda is achieved (flexible agenda costs). By introducing such flexible costs for agenda-setting, individuals attempting to thwart socially efficient proposals by putting forward their own proposals can be deterred from agenda-setting. In this respect, the non-observability of other people's utility is advantageous in achieving first-best allocations. It allows a society to set agenda costs at levels at which only project-winners will apply for agenda-setting, whereas project-losers will not.

Our central conclusion is that the combination of the following rules yields efficient provision of public projects: flexible and double majority rules, a ban on subsidies and flexible agenda costs.

Our second insight is that a higher dimensional uncertainty about the project parameters - e.g. who benefits, how large the benefits are and how large the share of beneficiaries is - may make it easier to design rules under a veil of ignorance from achieving first-best allocations. Higher dimensional uncertainty makes it possible to set agenda cost rules such that project-losers, who will not know how large the benefits are at the legislative stage, do not apply for agenda-setting. Such a deterrence of profit-losers from agenda-setting is desirable since project-losers have an incentive to prevent the adoption of socially desirable projects by making unattractive proposals.

Our third insight is that equal treatment of all individuals with respect to taxes prevents the society from achieving first-best allocations since the size of the required majority cannot vary with the share of taxed individuals. However, a more restricted equal treatment clause, when only the individuals who have to pay taxes must be treated equally with respect to taxation, does not destroy first-best allocations.

Overall, the paper highlights the fact that even under the liberal-democracy constraint and even if utilities are not observable for others, society can still achieve first-best allocations of public projects by sophisticated majority rules and agenda-cost rules.

The paper is organized as follows. In the next section, we provide detailed motivation for our approach. In section three, we introduce the model and the constitutional rules. In the fourth section, we discuss first-best constitutions depending on the uncertainty about project parameters at the constitutional stage. In the fifth section, we discuss 
dictatorial agenda-setting, the role of non-anonymous proposals and the case where there are only project-winners. In the last section, we summarize our conclusions and propose some avenues for further research.

\section{Motivation and Approach}

There are several motivations and justifications for this paper. First, we believe that we can provide a rationale why double majority rules are useful decision rules in practice. There are a variety of decision rules used in democracies with a double majority feature. For instance, in Switzerland and Australia two majorities are required to signify approval of certain laws: a majority of all electors voting and a majority of states. This is called double majority rule (see e.g. Saunders 2001). Moreover, in Australia a proposed law to alter the constitution must be passed by both the Parliament and the people, the latter voting directly in a referendum. Finally, many representative democracies have a bicameral Parliament and in most circumstances laws must be passed by both Houses. Since we are not examining a representative democracy or a hierarchy of federal and state levels, our double majority rules do not exactly match real-world examples. However, the reasons found in the paper for using double majority rules to restrict the taxation of minorities point in the same direction as the one pursued by constitutions in Australia and Switzerland (see e.g. Saunders (2001) and Feld and Kirchgässner (1998) for a recent survey).

Second, our analysis is closely related to the fundamental issues in mechanism design. Two main results in the area of mechanism design represent polar cases for this paper. First, in a mechanism design setting d'Aspremont and Gérard-Varet (1979) and Arrow (1979) show that the expected externality mechanism as a direct revelation mechanism yields an ex post efficient social choice implementable in Bayesian Nash equilibrium if agents' types are statistically independent and agents must participate in the mechanism. Second, the Myerson-Satterthwaite theorem (Myerson and Satterthwaite 1983) shows that there is no Bayesian incentive-compatible social choice function that is efficient ex post and where agents are free to opt out of the mechanism. The democratic mechanisms discussed in this paper force people to participate aftermath and thus are not subject to the Myerson-Satterthwaite impossibility theorem. However, we restrict 
our analysis to democratic mechanisms characterized as follows:

First, there is an agenda application stage where everybody can apply for agenda setting and the agenda setter is determined randomly which is one expression of equal agenda rights. Second, after a proposal has been made, only voting, i.e. yes/nomessages are allowed ${ }^{2}$ including the possibility of non-participation in the voting stage. Third, every individual has the same voting right which is equivalent to the anonymity principle introduced by May (1954). We call these three constraints the liberal democracy constraint on the set of mechanisms. Feasible mechanisms are called democratic mechanisms or, equivalently, democratic constitutions. Since the expected externality mechanism is not a democratic mechanism it is therefore unclear a priori whether we can reach efficiency or not.

A difficult issue arises in this context. Since we focus on democratic mechanisms, we cannot use the revelation principle to simplify the mechanism-design task as is usually done. The range of democratic mechanisms consists of all conceivable agendasetter rules, agenda and decision rules (which themselves are arbitrary functions of the project/finance package proposed by the agenda-setter subject to feasibility constraints), and the liberal-democracy constraint. As will become obvious, such functions neither need or ought to be continuous in all cases, e.g. when threshold majority rules are used. Therefore, even under the liberal-democracy constraint the range of possible mechanisms is extremely large. ${ }^{3}$ Accordingly, we employ a constructive or inductive approach.

Our approach is constructive in the sense that we design rules which must fulfill the liberal-democracy constraint, but should allow a society to achieve first-best allocations under various scenarios of uncertainty. An alternative approach would be in a first step to characterize all feasible mechanisms and in a second step to prove the possibility or impossibility of first-best allocations. While a formal description is possible in principle by making agenda-setter rules, agenda and decision rules become arbitrary functions of the proposal, it is not clear yet whether this approach allows for general characterization of democratic mechanisms which must be the long-term objective of

\footnotetext{
${ }^{2}$ This means that if a voter sends more or other messages, he will be neglected in the collective decision.

${ }^{3} \mathrm{As}$ long as we restrict all rules to piecewise continuous functions we obtain infinitely dimensional Riesz spaces comprehensively examined in Aliprantis and Border (2000).
} 
the research on democratic mechanisms. Since we can design mechanisms with novel rules to achieve first-best allocations, the constructive approach appears to be a useful substitute. ${ }^{4}$ The third motivation for our approach is the interest in new agenda-setter rules. As far as we know, flexible agenda costs, where costs depend on the share of supporting votes and on the requirement that agenda-setters must pay the highest tax they are proposing, are new rules that might be helpful in democratic decision-making.

Our paper is a study in constructive constitutional economics, as outlined in the classic contribution by Buchanan and Tullock (1962). Individuals decide under a veil of ignorance which rules should govern legislative decision-making. In a long tradition dating back to Rousseau, Harsanyi (1955), Mirrless (1971) and Wicksell (1896), Buchanan and Tullock (1962) have examined the costs and benefits of majority rules a society chooses behind a veil of ignorance. Aghion and Bolton (1998) have explicitly introduced contractual incompleteness for the design of optimal majority rules. In our paper following this incomplete-contract approach, we examine how democratic rules beyond majority rules with a fixed size of required yes-votes can help to achieve first-best allocations of public projects even if utilities for individuals cannot be observed by other citizens. ${ }^{5}$

The constitutional rules in our paper induce agenda-setters to propose projects which are only accepted if they are socially desirable and thus our constitutions induce efficient information aggregation. Our paper is thus broadly related to the recent literature on efficient information aggregation through voting. ${ }^{6}$ However, none of the existing papers in the literature is concerned with the design of constitutional rules for agenda-setting and decisions to implement efficient allocations of public projects.

\footnotetext{
${ }^{4}$ Moreover, our mechanisms do not depend on a priori distributions of project parameters and thus belong to the research program on prior free mechanisms. From private communication we are aware that several researcher are working on this program.

${ }^{5}$ It is open whether the complexity of the rules proposed in the paper may exceed those a society wants to incur. But the idea of using flexible and double majority rules and making agenda costs dependent on the share of supporting votes could be relevant for institutional designs in democracies.

${ }^{6}$ An important strand of literature has examined the validity of the Condorcet Jury Theorem which states that majority-rule voting allows efficient information aggregation. Austen-Smith and Banks (1996), Feddersen and Pesendorfer (1994, 1996) and Meyerson (1994) have shown that taking into account the possibility of strategic voting does allow generalization and reinforce the informational efficiency of voting. Others have relaxed the independence assumption and allow for correlated voters and still obtain efficient information aggregation (Berg 1993, Ladha 1992, Berend and Paroush 1998). For a concise survey see Piketty (1999). Piketty (2000) has developed a theory through which communicative voting can influence future elections. This is absent in our model.
} 


\section{Model and Constitutional Principles}

\subsection{Model}

The basic structure of our model builds on Romer and Rosenthal (1983) and in particular on Aghion and Bolton (1998). We consider a standard social choice problem of public project provision and financing. Time is indexed by $t=0,1$. The first period $t=0$ is the constitutional period. In the constitutional period a society of risk-neutral members decides how public project provision and financing should be governed in the legislative period. Citizens are indexed by $j \in[0,1]$.

In the legislative period, $t=1$, each citizen is endowed with $e$ units of a private consumption good. The community can adopt a public project with per capita costs $k>0$. Let $c_{j}$ denote the utility of agent $j$ from the provision of the public project. At $t=0$ the utility $c_{j}$ is unknown and hence can be interpreted as a random variable. For simplicity of presentation, we assume that $c_{j}$ can take two values (expressed in terms of the consumption good), $c_{j}=C_{h}>0$ (project-winners) and $c_{j}=C_{l}<C_{h}$ (projectlosers) with probability $p$ and $(1-p)$ respectively. Throughout the paper we assume that $C_{l}<0$ and that project-losers indeed are harmed by the public project. We comment in the final section on the way in which our results are affected by assuming $C_{l}>0$.

Moreover, we assume that citizen's utility types are distributed in a way such that aggregate uncertainty is canceled out. ${ }^{7}$ Thus, $p$ is equal to the fraction of winners.

Public projects must be financed by taxes. We assume that taxation is distortionary. Let $\lambda>0$ denote the shadow cost of public funds. Accordingly, taxation uses $(1+\lambda)$ of resources of taxpayers in order to levy 1 unit of resources for public projects and for transfers to citizens. Hence the overall per capita costs of the public project amount to $(1+\lambda) k$ and we can represent the project data with a vector $\mathcal{P}=\left(p, C_{h}, C_{l},(1+\lambda) k\right)$.

\footnotetext{
${ }^{7}$ The exact construction of individual randomness such that this statement holds can be found in Alos-Ferrer 1999 and works roughly as follows: Let $X$ be a random variable which takes the values $C_{h}$ and $C_{l}$ with probabilities $p$ and $1-p$ respectively. Let $I=[0,1]$ be the population of agents. By section 3.1 and 3.2 in Alos-Ferrer, there exists a population extension and thus a stochastic mapping assigning to each agent in $I$ a type, either $C_{h}$ or $C_{l}$ with the desired properties. We could also rely on the weaker forms of the strong law of large numbers developed in Uhlig (1996) and Al-Najjar (1996) where independence of individual random variables can be assumed and aggregate stability is the limit of an economy with finite characteristics.
} 
We use $t_{j}$ and $s_{j}$ to denote a citizen $j^{\prime} s$ tax payment or subsidy, respectively. We define the variable $g$ as indicating whether the public project is provided $(g=1)$ or not $(g=0)$. Assuming that $c_{j}$ is a private benefit that cannot be taxed, the utility $U_{j}$ of citizen $j$ in the legislative period is given by: ${ }^{8}$

$$
U_{j}=e+g c_{j}-t_{j}+s_{j}
$$

We drop the index $j$ in $U_{j}$ whenever convenient. Finally, the budget constraint of the society in the legislative period is given by

$$
\int_{0}^{1} t_{j} d j=(1+\lambda)\left[g k+\int_{0}^{1} s_{j} d j\right]
$$

We assume throughout the paper that $e$ is sufficiently larger than $C_{h}$, so that individuals can be taxed at a rate that is at least equal to the maximal benefits they may receive from the public project.

\subsection{Socially Efficient Solutions}

The fact that citizens are risk-neutral implies that, from an ex ante point of view, it is socially efficient to provide the public project if and only if

$$
C:=p C_{h}+(1-p) C_{l}>k(1+\lambda)
$$

and taxes are raised solely to finance the public project. Any redistribution activities are detrimental from an ex ante point of view. A socially efficient tax scheme, for instance, is one where a socially desirable public project is financed by project-winners and no subsidies are paid. In order to implement such a solution, a complete social contract would be necessary. We summarize our observation as follows.

\section{First-best Allocation:}

Any allocation that provides the public project if and only if $C>k(1+\lambda)$ and that raises taxes only to finance the public project is socially efficient.

An example for a first-best allocation is given by:

\footnotetext{
${ }^{8}$ All tax and subsidy functions $t_{j}$ and $s_{j}$, are assumed to be integrable and we will only discuss mechanisms when this condition is trivially fulfilled.
} 
(i) If $C>k(1+\lambda)$ then $g=1, t=\left\{\begin{array}{ll}k(1+\lambda) / p & \text { for project-winners } \\ 0 & \text { for project-losers }\end{array}\right.$ and
$\quad s_{j}=0$ for all $j$.

(ii) If $C \leq k(1+\lambda)$ then $g=0$ and $t_{j}=s_{j}=0$ for all $j$.

In the following we assume that complete social contracts cannot be written. As is usual in the incomplete contracting literature, we assume that future states of nature cannot be described precisely and therefore a constitution can only specify rules for future social decision-making. Moreover, individual utility levels cannot be observed by other persons. In particular, an agenda-setter faces the problem that he cannot impose taxation on project-winners only, because all persons are alike from his perspective. Given socially efficient allocations, it is important at this stage to identify the sources of inefficiencies that may arise in legislative decision-making: There are three types of inefficiencies:

- inefficient projects are proposed and adopted

- efficient projects are proposed, but rejected

- efficient projects are not proposed.

Implicitly, the latter two inefficiencies mean that delay in undertaking public projects is costly. In the paper we adopt the extreme assumption that not adopting efficient projects results in the status quo. As discussed in more detail in section 5, democratic mechanisms become more complex especially because of the third source of inefficiency. Democratic mechanisms must ensure that project-losers cannot set the agenda and block the adoption of efficient projects. Also in section 5, we discuss an example showing that much simpler mechanisms would solve the first two inefficiencies but not the third one. 


\subsection{The Game}

We consider the duality of constitutional and legislative periods as a substitute for the complete social contract, which cannot be written. At the constitutional stage, the society decides about the rules governing the legislative processes. The sequence of events for a decision process in this context is summarized as follows:

Stage 1: In the constitutional period, the society decides unanimously about the constitutional principles governing legislative decision-making.

Stage 2: At the start of the legislative period, citizens observe their own utility $c_{j}$. Citizens decide simultaneously whether to apply for agenda-setting $\left(\psi_{j}=1\right)$ or $\operatorname{not}\left(\psi_{j}=0\right)$.

Stage 3: Among all citizens that apply, one citizen $a \in[0,1]$ is determined randomly to set the agenda. The agenda-setter proposes a project/financing package $\left(g, t_{j}, s_{j}\right)_{j \in[0,1]}$. Denote this choice by $A_{a}$.

Stage 4: Given $A_{a}$, citizens decide simultaneously whether to accept $A_{a}\left(\delta_{j}\left(A_{a}\right)=1\right)$ or $\operatorname{not}\left(\delta_{j}\left(A_{a}\right)=0\right)$.

Note that if nobody applies for agenda-setting, the status quo will prevail. Moreover, individuals know at the voting stage who will be taxed and who will receive subsidies if the proposal is accepted. Obviously, the status quo also prevails if a proposal to change it does not receive enough yes-votes as required by the majority voting rule. Given a constitution with a set of principles discussed in the next section, we look at implementations in stages 2 to 4 . An equilibrium for the stages 2 to 4 can be described as a set of strategies

$$
\{\psi, A, \delta(\cdot)\}
$$

where $\psi=\left(\psi_{j}\right)_{j \in[0,1]}, A=\left(A_{a}\right)_{a \in[0,1]}, \delta=\left(\delta_{j}\right)_{j \in[0,1]}$ and $\delta_{j}=\delta_{j}\left(A_{a}\right)$ depend on the proposed agenda $A_{a}$. To derive an equilibrium, we will use weak dominance criteria and show that this dominance solution concept uniquely implements first-best allocations. ${ }^{9}$

\footnotetext{
${ }^{9}$ Since there is incomplete information about the utilities of the project, given a specific a priori distribution, the dominance solution concept also yields perfect Bayesian Nash equilibria.
} 
For the voting game in stage 4 and for the decision about applying for agenda-setting (stage 2) we will assume that

\section{- (EWS) Agents eliminate weakly dominated strategies.}

EWS is a standard assumption to eliminate the multiplicity of voting equilibria based on the trembling-hand perfection of Nash equilibria. In order to apply the dominance solution concept in all circumstances at the agenda-setting stage, two additional variants of weak dominance are used to obtain uniqueness. First, weak dominance for agenda application strategies is used, given uniqueness of voting equilibria and hence elimination of weakly dominant voting strategies. Second, if needed, we apply iterated weak dominance. The latter is required in situations as in proposition 1, where not applying for agenda-setting is weakly dominated only for project-winners. If, however, project-winners apply for agenda-setting and non-application by project-winners is eliminated, it will be weakly dominant for project-losers also to apply. All types of the weak dominance concept (see e.g. also Fudenberg and Tirole 1992) are assumed to be incorporated in (EWS).

We use $U_{j}\left(A_{a}, \Delta_{j}, \delta_{j}\right)$ to denote the utility payoff of agent $j$ given that an agenda $A_{a}$ is proposed by $a$ and given the votes $\Delta_{j}=\left(\delta_{i}\right)_{i \in[0,1] ; i \neq j}$ of all other citizens and his own vote $\left(\delta_{j}\right)$. In order to simplify the exposition, we assume that the following three tie-breaking rules are applied:

- (T1) Suppose that agent a has proposed the agenda $A_{a}$. If $U_{j}\left(A_{a}, \Delta_{j}, 1\right)=$ $U_{j}\left(A_{a}, \Delta_{j}, 0\right)$ for all possible votes $\Delta_{j}$ of the other agents, then agent $j$ will vote against the proposal if his net benefit $u_{j}=g c_{j}+s_{j}-t_{j}$ from the proposal is strictly smaller than zero; in all other cases he will vote yes. ${ }^{10}$

In order to formulate the second tie-breaking rule, we assume that the voting subgame has a unique equilibrium. ${ }^{11}$ In this case we can use $U_{j}\left(A_{a}\right)$ to define the utility level that an agent $j$ will achieve if agent $a$ has proposed the agenda $A_{a}$. Moreover, the set of all possible agendas is denoted by $\mathcal{A}$.

\footnotetext{
${ }^{10}$ Note that $U_{j}\left(A_{a}, \Delta_{j}, 1\right)=U_{j}\left(A_{a}, \Delta_{j}, 0\right)$ holds if a positive measure of voters say yes or no because we have a continuum of agents.

${ }^{11}$ We will show that (EWS) and (T1) imply a unique solution for the voting subgame for all constitutions under consideration.
} 
- (T2) If an agent $j$ cannot strictly improve his utility by agenda-setting, he will not apply for agenda-setting. ${ }^{12}$

- (T3) If an agenda-setter is indifferent as to an agenda which leads to $g=1$ and another which yields $g=0$, he will propose the former.

Note that $U_{j}\left(A_{j}\right)$ includes the optimal voting strategies of all agents and that of agent $j$ in particular. In what follows we will always assume - without referring to the fact explicitly - that (EWS), (T1), (T2) and (T3) are applied. We are now in a position to characterize the expected utility level that a particular constitution can deliver. We can say that a constitution, denoted by $C O$, implements an expected utility $U$ if, given agents have agreed on $C O$ in stage 1, the following holds: If (EWS), (T1), (T2) and (T3) are applied, all possible equilibria under the constitution $C O$ yield the expected utility $U$. Non-uniqueness of equilibria can occur in the agenda-setting stage with respect to who applies for agenda-setting and to the distribution of taxes. A formalization of this implementation requirement can be found in Gersbach (2000).

We call a constitution first-best if it implements the expected utility $\bar{U}_{\text {opt }}$ induced by the socially efficient contract, namely

$$
\bar{U}_{\text {opt }}= \begin{cases}e+C-(1+\lambda) k & \text { if } C-(1+\lambda) k>0 \\ e & \text { else }\end{cases}
$$

Since individuals are identical at the constitutional stage, we can apply the unanimity rule for the society's decision about the constitutional rules. Then, in order to prove that a constitution under consideration is first-best, we will show that

- applying and voting strategies are unique;

- if $C-(1+\lambda) k \geq 0$, then at least one individual applies for agenda-setting and all agenda-setters propose the socially efficient project which will be adopted.

- if $C-(1+\lambda) k<0$, then nobody will apply for agenda-setting, i.e. $\psi_{j}^{*}=0$ for all $j$.

\footnotetext{
${ }^{12}$ The rule (T2) could also be justified by a very small but positive cost of agenda-setting.
} 
A constitution that implements the first-best solution therefore must be associated with unique applying and voting strategies and proposals of $g=1$ if and only if the project is efficient. However, it is not necessary for the financing proposal to be unique with respect to the distribution of taxes.

\subsection{Constitutional Principles}

We assume that in the legislative stage individuals cannot observe whether other individuals benefit or lose from the public project. They only observe their own utility gain or loss. The rules in the constitution now have to specify:

1. whether there is a special treatment of the agenda-setter (agenda-setter rules).

2. which restrictions on the agendas can be proposed, i.e. definition of all constitutional agendas (agenda rules). An agenda consists of a project proposal and a financing package.

3. how the nation decides about a proposal (decision rules).

In order to formulate the constitutional rules we introduce the following notation:

\section{Notation}

Let $A$ be an arbitrary agenda. We use $n_{T}$ to denote the fraction of citizens that have to pay positive taxes. We use $r$ to denote the share of yes-votes for a proposal to change the status quo. By analogy, $r_{T}$ and $r_{N T}$ denote the share of yes-votes for a proposal among the set of taxed and non-taxed individuals respectively. Furthermore, we use $\bar{t}$ to denote the average tax rate proposed among the set of taxed people and $T=\int_{0}^{1} t_{j} d j$ to denote the total tax payments proposed in A. Finally, we use $t^{\mathrm{min}}$ to denote the minimal tax rate of an agenda $A$.

Note that

$$
\bar{t}:=\frac{\int_{0}^{1} t_{j} d_{j}}{\int_{0}^{1} 1\left\{t_{j}>0\right\} d j}, \quad t^{\min }=\min _{t_{j}>0}\left\{t_{j}\right\}
$$


Since the set of feasible rules under the liberal-democracy constraint is still very large, we use a sequential approach i.e. we invent rules which will be helpful to achieve firstbest allocations for a constitutional problem under consideration. ${ }^{13}$ We will need the following options to design appropriate constitutional rules or democratic mechanisms:

\section{Agenda-setter rules}

- Costs of agenda-setting [CA(b)]

The agenda-setter has to pay a fixed amount of $b>0$ if his agenda does not lead to the provision of the public project.

- Flexible costs of agenda-setting [CA $\left.\left(b_{1}, b_{2}(r)\right)\right]$

The agenda-setter has to pay a fixed amount of $b_{1} \geq 0$ if his agenda does not lead to the provision of the public project. Additionally, he pays $b_{2}(r)$ if the share of supporting votes is smaller than $r(0 \leq r \leq 1)$. Clearly, $C A\left(b_{1}, 0\right)$ corresponds to fixed costs of agenda setting.

Agenda Rules

- No subsidies [NS]

The agenda-setter is not allowed to propose any subsidies.

- The financing package must satisfy the budget constraint.

\section{Decision Rules}

- $m$-majority rule $[\boldsymbol{M}(\mathrm{m})]$

If a proposal to change the status quo receives a majority of $m$ percent of the citizens, the proposal is adopted.

- Flexible majority rule

This rule divides the population into the part $P_{T}$ that - according to the proposal - has to pay positive taxes $\left(t_{j}>0\right)$ and the rest $P_{N}$ (of the population). A proposal is adopted if it receives an $m$ percent majority of the

\footnotetext{
${ }^{13}$ Since the space of feasible mechanisms is quite large, the sequential approach appears to be more fruitful than a general design approach. However, with our approach, we cannot characterize the set of all possible constitutions which would lead to first-best allocations.
} 
citizens, where $m\left(n_{T}, T, \bar{t}\right)$ may depend on the fraction $n_{T}$ of taxed people in the population, on the total taxes $T$ and on the average tax rate $\bar{t}$ proposed in the agenda.

The following special cases of the flexible majority rule are important for our discussion:

- Fixed majority rule, $m\left(n_{T}, T, \bar{t}\right)=m$.

- Threshold majority rule (fixed threshold) [TMf $\left.\left(m_{1}\left(n_{T} \leq q\right), m_{2}\right)\right]$. Under this rule $m$ jumps from $m_{1}$ to $m_{2}$ when the proportion of taxed people reaches the threshold level $q$, i.e.

$$
m= \begin{cases}m_{1} & \text { if } \quad n_{T} \leq q \\ m_{2} & \text { else }\end{cases}
$$

- Threshold majority rule (variable threshold) [TMv $\left.\left(m_{1}\left(n_{1} \leq q\right), m_{2}\right)\right]$

$$
m= \begin{cases}m_{1} & \text { if } \quad n_{T} \leq q\left(T, \bar{t}, t^{\mathrm{min}}\right) \\ m_{2} & \text { else }\end{cases}
$$

\section{- Double majority rule}

Under this rule, a proposal is only accepted if it is adopted among the set of taxed individuals and among the set of non-taxed individuals.

Double majority rules can be combined with flexible majority rules. For instance:

- Fixed double majority rule $m[\mathbf{D M}(m)]$.

A proposal is adopted if $r_{T} \geq m$ and $r_{N T} \geq m$.

- Threshold double majority rule [DTMf $\left.\left.\left(m_{1}\left(n_{T} \leq q\right), m_{2}\right)\right)\right]$.

Under this rule $m$ jumps from $m_{1}$ to $m_{2}$ when the proportion of taxed people reaches the threshold level $q$. A proposal is accepted if $r_{T} \geq m$ and $r_{N T} \geq m$.

Double majority rules require that the shares of yes-votes among taxed individuals and among non-taxed individuals are sufficient in themselves to adopt the project. A weaker requirement is that the share of yes-votes among the taxed population must be at least equal to the share of yes-votes in the non-taxed part 
of the population. The conclusions in the paper do not depend on which concept of majority rules is used.

Note that both majority rules and [CA (b)] may depend on information generated by the proposal $\left(n_{T}, \bar{t}, T, t^{\mathrm{min}}\right)$. Flexible majority rules have been introduced in Erlenmaier and Gersbach (1999). The novel rules in this paper are double majority rules and flexible agenda costs. Moreover, note that the constitutionality check occurs both at the proposal and at the voting stage. If a proposal or the majority voting outcome violates one of the agenda or decision rules, then the status quo prevails, since the constitution is violated and the proposal is void. This implies that the constitutional check on proposals may only be possible after votes have been cast.

\section{First-best Constitutions}

Our major assumption is that at the legislative stage individuals cannot observe whether other individuals are project winners or losers. The remaining question is which entries of the project vector $\mathcal{P}=\left(p, C_{h}, C_{l},(1+\lambda) k\right)$ are verifiable in front of a constitutional court in the legislative period. When some entries of $\mathcal{P}$ are verifiable in a constitutional court, constitutional rules can be formulated dependent on those parameters even if they are not known in the constitutional period, since a court can determine them in the legislative period.

An equivalent alternative view is that instead of being verifiable in the legislative period some parameters of $\mathcal{P}$ are known in the constitutional period and hence can be written into the constitution directly. In the following, we describe our results in terms of the second view. Note that the greater the number of parameters in $\mathcal{P}$ known at the constitutional stage, the more likely it is that one can find a constitution that implements the first-best solution and the less complex such a constitution will be. Therefore, we will present our results in a descending order of assumptions about the parameters known at the constitutional stage.

In each section we introduce more uncertainty about the parameters of the public project. This exposition will show that the complexity of optimal constitutional rules increases as more parameters at the constitutional stage are considered uncertain. 


\subsection{Uncertainty about Winners and Losers}

We begin with the simplest case where all elements of $\mathcal{P}=\left(p, C_{h}, C_{l},(1+\lambda) k\right)$ are known at the constitutional stage while there is uncertainty for the individuals whether they will be project winners or losers. And note that an agenda-setter cannot observe whether other individuals are project winners or losers. We obtain:

\section{Proposition 1}

Suppose that all elements of the project vector $\mathcal{P}=\left(C_{h}, C_{l}, p,(1+\lambda) k\right)$ are known at the constitutional stage.

(i) If $C \geq k(1+\lambda)$, the constitution $C O_{1}:=\left\{\left[C A\left(-C_{l}\right)\right],[N S],[M(p)]\right\}$ is first-best.

(ii) If $C<k(1+\lambda)$, the constitution $C O_{2}:=\left\{\left[C A\left(-C_{l}\right)\right],[N S],[M(1)]\right\}$ is first-best.

The proof of proposition (1) is given in the appendix. Proposition (1) shows the rather obvious point that there is no problem in achieving a first-best allocation if project data are known at the constitutional stage even if the agenda-setter does not know who benefits from the public project. However, since the first-best constitutions differ considerably for socially efficient and socially inefficient projects, it is unclear what is to be done if there is uncertainty in $t=0$ whether projects are efficient or not. This problem is addressed in the next section.

\subsection{Uncertainty regarding $\mathrm{C}_{\mathrm{h}}$}

We assume in this section that there is uncertainty in $t=0$ about the size of the utility gain $C_{h}$ and therefore whether projects are socially valuable or not. If we assume that $C_{h}$ is not known at the constitutional stage, we have to use a flexible majority rule in order to achieve a first-best allocation. To make the working of this rule more transparent, we will use a slightly different representation of the rule for socially efficient public project provision:

$$
\begin{gathered}
g=1 \text { if and only if } C_{h}>C_{h}^{*} \text {, where } \\
C_{h}^{*}:=\min \left\{C_{h} \geq 0 \mid p C_{h}+(1-p) C_{l} \geq(1+\lambda) k\right\}
\end{gathered}
$$


and taxes are raised solely to finance the public project.

Hence, for given $p, C_{l}$ and project costs $(1+\lambda) k$, the utility level $C_{h}^{*}$ is the smallest benefit level at which it is socially beneficial to provide the public project. We obtain:

\section{Proposition 2}

Suppose that $C_{h}$ is not known at the constitutional stage. Then the constitution

$$
\begin{gathered}
C O_{3}:=\left\{[C A(b)],[N S],\left[\operatorname{TMf}\left(p\left(n_{T} \leq q^{*}\right), 1\right)\right]\right\} \\
\text { with } q^{*}=\frac{k(1+\lambda)}{C_{h}^{*}} \\
\text { and } b \text { sufficiently high }
\end{gathered}
$$

is first-best.

The proof is given in the appendix. Proposition (2) indicates that a first-best allocation can be achieved by the combination of costly agenda-setting, a ban on subsidies, and flexible majority rules. Essentially, an agenda-setter is able to form a majority if and

only if $C_{h} \geq C_{h}^{*}$, since he can tax a fraction of $q^{*}$ individuals by $t=C_{h}^{*}$ which is sufficient to finance the public project. Since tax rates are not higher than $C_{h}^{*}$, taxed project-winners still support the proposal. The high costs of agenda-setting deter project-losers from applying for agenda-setting and proposing $g=0$, since projectlosers do not know whether $C_{h}$ is larger or smaller than $C_{h}^{*}$. A project-winner will apply for agenda-setting if and only if he observes that $C_{h}$ is larger than $C_{h}^{*}$ and $g=1$ can be therefore implemented. The fact that individuals cannot observe the utilities of other agents makes it possible to set agenda costs so high that project-losers will not want to face the risk of defeat.

\subsection{Uncertainty regarding $p$}

In this section we assume that individuals do not know whether they benefit from the public project at the constitutional stage, and how large the share of project-winners is. Now the problem becomes more subtle since neither a project-winner nor a project loser can observe the proportion of project-winners and thus whether a proposal is likely to be accepted or not. Nevertheless, a modified constitution will ensure that a first-best allocation can be achieved. Again we represent the first-best public project provision rule in a convenient way. 


$$
\begin{gathered}
g=1 \quad \text { if and only if } p \geq p^{*}, \quad \text { where } \\
p^{*}:=\min \left\{p \geq 0 \mid p C_{h}+(1-p) C_{l} \geq(1+\lambda) k\right\}, p^{*}=\frac{(1+\lambda) k-C_{l}}{C_{h}-C_{l}} \\
s_{j}=0, \forall_{j}
\end{gathered}
$$

We use $\operatorname{Pr}\left\{p \geq p^{*}\right\}$ and $\operatorname{Pr}\left\{p<p^{*}\right\}$ to denote the probabilities that the share of project-winners is larger and smaller than $p^{*}$, respectively. We obtain

\section{Proposition 3}

Suppose that $p$ is not known at the constitutional stage and that

$$
-C_{l} \leq \frac{\operatorname{Pr}\left\{p \geq p^{*}\right\}(1+\lambda) k}{\operatorname{Pr}\left\{p<p^{*}\right\}}
$$

Then the constitution

$$
C O_{4}:=\left\{[C A(b)],[N S],\left[\operatorname{TMf}\left(p^{*}\left(n_{T} \leq p^{*}\right), 1\right)\right]\right\}
$$

where $b$ must fulfill

$$
-C_{l} \leq b \leq \frac{\operatorname{Pr}\left\{p \geq p^{*}\right\}(1+\lambda) k}{\operatorname{Pr}\left\{p<p^{*}\right\}}
$$

is first-best.

When there is only uncertainty about $p$, there is no possibility of deterring projectlosers from setting the agenda by making agenda costs prohibitively high, as this will act as a deterrent for everyone. However, project losers must be deterred from making unconstitutional proposals. ${ }^{14}$ Moreover, it follows from proposition (3) that the constitutional problem is already sufficiently delicate if $p$ is not known at the constitutional stage, because the successful implementation of $\mathrm{CO}_{4}$ depends on parameters. However, as the next section shows, the joint uncertainty about the size of the benefits and the share of project-winners improves the possibilities likelihood for democracies to achieve first-best allocations because agenda-setting incentives for project-winners and losers diverge.

\subsection{Uncertainty regarding $C_{h}$ and $p$}

In this section we address the more complex problem proved by the fact that the size of the benefits from public projects and the proportion of project-winners are not known

\footnotetext{
${ }^{14} \mathrm{By}$ extending the argument one can show that no constitution consisting of a subset of rules introduced in subsection 3.4 yields first-best allocations under any distributional assumption about $p$.
} 
at the constitutional stage. We assume that at the constitutional stage $p$ and $C_{h}$ are stochastically independent and distributed according to some density functions with $p \in[\underline{p}, \bar{p}]$ and $C_{h} \in\left[\underline{C}_{h}, \bar{C}_{h}\right] .0 \underline{p}>0$ and $\underline{C}_{h}>0$ are the lowest possible realizations. $\bar{p} \leq 1$ and $\bar{C}_{h}>\underline{C}_{h}$ are the upper bounds of $p$ and $C_{h}$. We assume that $\underline{C}_{h}<k(1+\lambda)$ and that $\operatorname{Pr}\left\{C_{h}<k(1+\lambda)\right\}$ is strictly positive. Again, we reformulate the socially efficient public good provision in a convenient way.

$$
\begin{gathered}
g=1 \quad \text { if and only if } p\left(C_{h}\right) \geq p^{*}\left(C_{h}\right) \quad \text { where } \\
p^{*}\left(C_{h}\right):=\min \left\{p \geq 0 \mid p C_{h}+(1-p) C_{l} \geq(1+\lambda) k\right\}, p^{*}\left(C_{h}\right)=\frac{(1+\lambda) k-C_{l}}{C_{h}-C_{l}} \\
s_{j}=0, \forall_{j}
\end{gathered}
$$

Hence, for given $C_{h}, p^{*}\left(C_{h}\right)$ is the smallest proportion of project-winners for which it is socially beneficial that the public project be provided. Note that $p^{*}$ is decreasing in $C_{h}$. We also define

$$
\hat{C}_{h}:=\frac{(1+\lambda) k-(1-\bar{p}) C_{l}}{\bar{p}}
$$

Thus $\hat{C}_{h}$ is the benefit level at which the society is indifferent with regard to undertaking the public project if the share of project-winners is equal to the upper bound $\bar{p}$. We obtain:

\section{Proposition 4}

Suppose that $C_{h}$ and $p$ are not known at the constitutional stage. Then, the following constitution implements a first-best solution:

$$
\begin{aligned}
C O_{5}:=\left\{\left[C A\left(b_{1}\left(t^{\mathrm{min}}\right), b_{2}(r)\right)\right],[N S],\left[D T M v\left(p^{*}\left(t^{\mathrm{min}}\right)\left(n_{T} \leq p^{*}\left(t^{\mathrm{min}}\right)\right), 1\right)\right]\right\} \\
\text { with } p^{*}\left(t^{\mathrm{min}}\right)=\frac{(1+\lambda) k-C_{l}}{t^{\mathrm{min}}-C_{l}} \\
b_{1}\left(t^{\mathrm{min}}\right)= \begin{cases}0 & \text { if } t^{\mathrm{min}} \geq \hat{C}_{h} \\
b_{1} & \text { otherwise }\end{cases} \\
b_{2}(r)= \begin{cases}0 & \text { if } r \geq \underline{p} \\
b_{2} & \text { otherwise }\end{cases} \\
\text { and } b_{1}, b_{2} \text { sufficiently large. }
\end{aligned}
$$


The proof is given in the appendix. An important observation from proposition (4) is that the joint uncertainty about $C_{h}$ and $p$ can make it easier to achieve first-best since $\mathrm{CO}_{5}$ works under any circumstances, whereas $\mathrm{CO}_{4}$ can fail. The additional uncertainty about $C_{h}$ makes it possible to set flexible agenda costs at a level such that project-losers do not apply for agenda-setting in equilibrium because they do not know $C_{h}$, whereas project-winners do. Project-winners apply for agenda-setting if and only if $C_{h} \geq \hat{C}_{h}$. In such a case, both costs of agenda-setting can be avoided since taxes can be set to be smaller than $C_{h}$, thus ensuring $r \geq \underline{p}$.

\section{Discussion and Alternative Democratic Mecha- nisms}

\subsection{Dictatorial Agenda-Setting}

The preceding section indicates that democratic constitutions become more complex the more uncertainty dimensions are present. The main reason for the rapidly increasing sophistication of rules is that all three potential inefficiencies in section 2.2 need to be overcome by democratic mechanisms. If only the first two inefficiencies had to be dealt with, much simpler first-best mechanisms would exist. ${ }^{15}$ Suppose that the agenda is set by a benevolent dictator. Then the third source of inefficiency would be automatically avoided and we could consider the following game.

Stage 1: In the constitutional period, society decides unanimously about the constitutional principles governing legislative decision-making.

Stage 2: At the start of the legislative period, the benevolent agenda-setter proposes a project/financing package $\left(g, t_{j}, s_{j}\right)_{j \in[0,1]}$. Denote this choice by $A_{a}$.

Stage 3: Given $A_{a}$, citizens decide whether to accept the proposal $\delta_{j}\left(A_{a}\right)=1$ or not $\left(\delta_{j}\left(A_{a}\right)=0\right)$.

As an example of simpler mechanisms, we explore the design of constitutions when there is uncertainty about winners and losers and uncertainty regarding the share of project-winners, i.e. uncertainty regarding $p$. Then, we obtain:

\footnotetext{
${ }^{15} \mathrm{I}$ am grateful to a referee for this suggestion and the optimal mechanism.
} 


\section{Proposition 5}

Suppose that $p$ is not known at the constitutional stage and agenda-setting is dictatorial and benevolent. Then the constitution

$$
C O_{6}=\left\{[N S],\left[M\left(p^{*}\right)\right]\right\}
$$

where

$$
p^{*}:=\min \left\{p \geq 0 \mid p C_{h}+(1-p) C_{l} \geq(1+\lambda) k\right\}
$$

is first-best.

The proof follows directly from the first two steps in the proof of proposition 3 since a benevolent agenda-setter proposes $g=1$ if and only if $p \geq p^{*}$ and in this case can set the tax rates $t=(1+\lambda) k$ for all individuals.

Several remarks need to be made at this point. First, it is important that the benevolent agenda-setter maximizes aggregate utility and therefore proposes projects if welfare in a utilitarian sense can be improved although project losers are worse off compared to the status quo. Second, under benevolent and dictatorial agenda-setting the ban on subsidies, $N S$, in constitution $\mathrm{CO}_{6}$ could even be dropped. Third, if agenda-setting is determined randomly and thus all agents have the same chance to set the agenda as in the previous sections, the constitution $\mathrm{CO}_{6}$ is not first-best. All individuals would apply for agenda-setting. If a project-loser could determine the agenda, he would propose $g=0$ since, because of $N S$, he loses when the project is adopted. This problem could only be avoided by dropping $N S$, but then inefficiencies arise from excessive taxation to generate subsidies, thus increasing tax distortions. Therefore, the simple mechanism in this section does not yield first-best allocations under democratic agenda-setting.

Fourth, when there is uncertainty about $p$ and $C_{h}$ the dictatorial and benevolent agenda-setter would need to possess information about the realization of $C_{h}$ in order to use simpler constitutions than in the previous sections. This might not be the case. Moreover, under democratic agenda-setting it appears plausible from the previous sections that the combination of flexible and double majority rules, a ban on subsidies, and flexible agenda costs are needed for first-best allocations in case $p$ and $C_{h}$ are not known ex ante because project-losers must be deterred from agenda-setting and project-winners should only apply for agenda-setting if the project is socially desirable. 


\subsection{Equal Treatment Rules}

An important feature of the constitutions considered so far is that individuals can be - and are - treated differently with respect to taxation. An agenda-setter can make non-anonymous proposals and can impose positive taxes on other individuals and not on themselves. In this section we consider whether this feature is vital to our arguments. For this purpose we consider two constitutional treatment rules. We denote by ETT the requirement that a proposal is only constitutional if all individuals are treated equally with respect to taxes, i.e. $t_{j}$ is the same for all individuals. Moreover, we denote by ETTaxed the treatment rule which means that all individuals who are taxed (i.e. for whom $t_{j}>0$ ) must be treated equally with respect to taxation. As propositions 3 and 4 illustrate, imposing ETTaxed in addition to the constitutions under consideration would not destroy the first-best allocation because equilibrium proposals satisfy ETTaxed and further constraints on out-of-equilibrium strategies do not destroy the equilibrium.

The situation is different, however, if ETT is imposed. Consider the situation where $p$ and $C_{h}$ are not known at the constitutional stage. Then, the constitution $\mathrm{CO}_{5}$ together with the requirement ETT fails to implement first-best allocations. The argument runs as follows. A first-best proposal in case $C \geq k(1+\lambda)$ must always be $g=1$ and $t=k(1+\lambda)$ for all individuals because of ETT. Since the majority requirement can depend on the proposal but first-best proposals cannot vary in terms of the fraction of taxed individual $n_{T}$ or in the pattern of taxation and subsidization across agents, majority rules must be a fixed real number, say $m^{*}$, for all first-best proposals in the case $C \geq k(1+\lambda)$. As long as there is a positive probability for $C>k(1+\lambda)$ or $C<k(1+\lambda)$, there always exist realizations of parameters $C_{h}$ and $p$ such that either $p<m^{*}$, but $C>k(1+\lambda)$ or $p>m^{*}$ but $C<k(1+\lambda)$ and $p C_{h}>k(1+\lambda)$. As first-best constitutions must impose $N S$, any proposal with $g=1$ and $t=k(1+\lambda)$ for all individuals in case $p<m^{*}$ would be rejected since a share of $1-p$ individuals (project-losers) would vote against it. In the second case, a project-winner who can set the agenda can ensure that $g=1$ is adopted despite $C<k(1+\lambda)$. Therefore $\left\{\mathrm{CO}_{5}, E T T\right\}$ is not first-best. Since the preceding argument holds for any constitution involving ETT, we summarize this observation in the following proposition. 


\section{Proposition 6}

Suppose that $p$ and $C_{h}$ are not known at the constitutional stage. There then exists no constitution including ETT that is first-best if there is uncertainty as to whether $C>k(1+\lambda)$ or $C<k(1+\lambda)$.

\subsection{Only Project-Winners}

Throughout the paper we have assumed $C_{l}<0$ and that project-losers indeed are harmed by the project. Examples such as roads, labor market reforms or scale-downs in the defense industry may fall in this category. But it is still important to see how the democratic mechanisms need to be adjusted in the case $C_{l} \geq 0$. Since the proofs use the fact $C_{l}<0$, all constitutions can be applied for $C_{l} \geq 0$ as well. The only exception is proposition 1, where agenda-setting costs can be skipped or be set as $C A\left(\max \left\{\left[0,-C_{l}\right]\right\}\right)$ for the general case when $C_{l}$ can be positive or negative.

There exists, however, an important difference between $C_{l}>0$ and $C_{l}<0$. In the case $C_{l}>0$, it may not be necessary to deter agents from agenda-setting since they can always benefit potentially from $g=1$ by proposing zero taxes for themselves. Therefore, simpler mechanisms may again be first-best in the case $C_{l}>0$. As an example, suppose that $C_{l}>0$ and $p$ is not known at the constitutional stage. Then, since agents with $C_{h}$ or $C_{l}$ will propose $g=1$ if they can determine the agenda (including zero taxes for themselves), the simple constitution $C_{6}=\left\{[N S],\left[M\left(p^{*}\right)\right]\right\}$ will implement the first-best allocation. However, if there is uncertainty regarding $C_{h}$ and $p$, such simple constitutions are not first-best since deterrence from agenda-setting becomes again important. Constitutions such as $\mathrm{CO}_{5}$ are required since project-losers do not know whether the project is efficient and therefore should not set the agenda and projectwinners should only apply for agenda-setting if the project is socially desirable.

\section{Conclusions}

Our analysis suggests that democracies, viewed as the liberal-democracy constraint on the set of social mechanisms, can deliver socially desirable results if agenda-cost rules are combined with flexible and double majority rules. 
There are a number of extensions that should be taken up by future research. First, how can the ideas in this paper be applied to situations with an arbitrary number of different utility levels from the project? By setting the minimal tax at a sufficiently high level, it will still be possible to deter all individuals not eligible for the highest project benefits from applying for agenda-setting. But whether precise socially efficient implementation can be achieved is unclear, since taxation of intermediate beneficiaries cannot be tailored to their actual benefit level, this being unobservable for agendasetters.

Second, does the principle that higher dimensional uncertainty can make it easier to achieve socially optimal allocations extend to other situations in which there is even more uncertainty about project parameters at the constitutional stage? Our current conjecture is that it is impossible to design a constitution under the liberaldemocracy constraint which implements a first-best allocation if there is uncertainty about all project parameters. If this conjecture is true, our results could suggest a role for constitutional courts in the provision of public projects. That role would be an assessment of negative utilities from a public project in order to allow the efficient working of democratic constitutions.

Third, will the possibility of amendments or second proposals at the legislative stage help to generate better outcomes? In our model, such counterproposals are not necessary, indeed they are unwelcome, since individuals who gain less from a proposal than others have the opportunity to wait for better proposals which, in turn, could lead to rejections of socially desirable proposals.

Fourth, flexible and double majority rules require open ballots and are therefore best suited for smaller communities. It appears to be possible, however, that new internet technologies can allow anonymous identification of votes and persons even in cases of mass voting (e.g. the discussion in Walker and Akdeniz 1997). Thus, the internet could alleviate the practical implementation problems of democratic constitutions discussed in the paper. Tackling these and further issues might enhance the potential that societies have for using democratic mechanisms to allocate public projects efficiently. 


\section{Appendix}

The following simple observation will be needed for all proofs:

\section{Lemma 1}

Suppose that citizens have agreed on one constitution in stage 1. Then, given an agenda $A_{a}$, the voting strategies are unique, namely $\delta_{j}^{*}\left(A_{a}\right)=1$ if the net benefit $u_{j}=g c_{j}+s_{j}-t_{j}$ from $A_{a}$ is nonnegative and $\delta_{j}^{*}\left(A_{a}\right)=0$ otherwise.

Lemma 1 follows directly from EWS and the tie-breaking rule (T1), which imply that citizen $j$ votes yes if $u_{j} \geq 0$ and no otherwise.

\section{Proof of proposition 1:}

(i) We first consider part $(i)$ of the proposition. We claim that under $C O_{1}$ there exists a unique subgame perfect equilibrium in which all individuals apply for agenda-setting and propose $g=1$ and $t_{j}=(1+\lambda) k$ for $j \neq a$. Thus, we claim that $C O_{1}$ implements first-best.

The agenda-setter can tax all other individuals by $t=(1+\lambda) k$. Since $C_{h}>$ $C>k(1+\lambda)$, the proposal $\left(g=1, t_{j}=(1+\lambda) k \forall_{j}\right.$, with $\left.j \neq a, s_{j}=0 \forall_{j}\right)$ will be supported by all project-winners and therefore receives a $p$-majority as required for adoption. Since an agenda-setter can always propose zero taxes for himself, his utility is either $e+C_{l}$ (if project-loser) or $e+C_{h}$ (if project-winner) if he proposes $g=1$ with the above financing scheme. Therefore, applying for agenda-setting is a weakly dominant strategy for project-winners.

If the proposal of an agenda-setter is unconstitutional or is not adopted, his utility is $e+C_{l}$ because of the agenda-setting costs. If an individual does not apply for agenda-setting, he risks paying taxes if others apply for agenda-setting. And because of $[N S]$ he will never receive subsidies. Therefore, given that project-winners apply for agenda-setting, iterated elimination of weakly dominated strategies implies that project-losers also apply for agenda-setting under the constitution $C O_{1}$. Because of our tie-breaking rules, project-losers who can determine the agenda will propose $g=1$ as well. Therefore, the constitution $\mathrm{CO}_{1}$ is first-best. 
(ii) The second part follows from the observation that project-losers never support a proposal $g=1$ since they cannot receive subsidies. Therefore no agenda-setter can form a majority for $g=1$. Thus, no agent applies for agenda-setting because of agenda-setting costs and the status quo prevails.

\section{Proof of proposition 2:}

(i) Suppose that a project-winner applies for agenda-setting and can determine it. Since he observes his own utility level, he knows that other project-winners will receive the same utility. Suppose that the agenda-setter observes that his utility $C_{h}$ is greater than $C_{h}^{*}$. Then the agenda-setter can propose $g=1$ and

$$
t=\left\{\begin{array}{lll}
C_{h}^{*} & \text { for } & q^{*} \text { individuals } \\
0 & \text { for } & \text { others } \\
0 & \text { for } & \text { himself }
\end{array}\right.
$$

Since tax revenues are equal to $q^{*} C_{h}^{*}=k(1+\lambda)$ by definition of the critical share $q^{*}$, the public project can be financed. Since $n_{T}=q^{*}$, only $p$ individuals are needed to support the proposal. Since taxed project-winners benefit because $C_{h}>t=C_{h}^{*}$ and untaxed project-winners benefit a fortiori, the proposal is supported by all project-winners and thus will be adopted because the $p$-majority rule applies. Only the agenda-setter can avoid the risk of being taxed.

Suppose that $C_{h}<C_{h}^{*}$. Since project-losers never support a proposal with $g=1$, the agenda-setter needs the yes-votes of all project-winners. Hence, he cannot impose a very high tax on a small fraction of the population because this would imply that a share of the project-winner group rejects the proposal since the identities of winners and losers are unknown to the agenda-setter. ${ }^{16}$ The other possibility is to tax a larger fraction of the population with a tax rate that is not higher than $C_{h}$. This, in turn, implies that the proportion of taxed people must be larger than $q^{*}$ in order to satisfy the budget constraint. If, however, $n_{T}>q^{*}$,

\footnotetext{
${ }^{16}$ The argument is a consequence of the strong law of large numbers which implies that every positive measure of individuals contains a positive measure of project-winners.
} 
the unanimity rule applies and will lead to a rejection of $g=1$. Therefore, the status quo prevails, which, in turn implies that the agenda-setter is better off not applying for agenda-setting, because of $[C A(b)]$ and $b>0$.

To sum up, if $C_{h} \geq C_{h}^{*}$, project-winners have a weakly dominant strategy to apply for agenda-setting and thus they will apply for agenda-setting in equilibrium.

(ii) Suppose that a project-loser can determine the agenda. Since he only observes his own utility $C_{l}$, he does not know whether $C_{h}$ of project-winners is larger or smaller than $C_{h}^{*}$. We distinguish two cases. Suppose that the probability that $C_{h}<C_{h}^{*}$ is zero. Then he can do the same as the project-winner who can determine the agenda. The project-loser as an agenda-setter will receive utility $C_{l}$, which is slightly better than not applying for agenda-setting and being subject to the risk of taxation. In this case the socially optimal allocation is also achieved when a project-loser sets the agenda. Suppose now that the probability of $C_{h}<C_{h}^{*}$ is positive. If the project-loser applies for agenda-setting, he risks $C_{h}<C_{h}^{*}$ and thus he cannot form a majority in favor of $g=1$ by using the same arguments as under $(i)$ and he will suffer a loss of $b$. If $b$ is sufficiently high, the expected utility from agenda-setting can be made smaller than without because the maximal tax rate is limited by $C_{h}^{*}$. Therefore, by setting $b$ sufficiently high, not applying for agenda-setting is a weakly dominant strategy for project-losers.

(iii) Summarizing, under $\mathrm{CO}_{3}$ there exists a subgame perfect equilibrium $\psi_{j}=1$ if and only if individual $j$ is a project-winner and $C_{h} \geq C_{h}^{*}$. An agenda-setter proposes $g=1$ and $t_{j}=C_{h}^{*}$ for $q^{*}$ individuals. $C_{3}$ implements a first-best allocation.

\section{Proof of proposition 3:}

(i) Suppose that $p<p^{*}$. Since subsidies are forbidden, a share of $1-p$ of the voters will reject any proposal to introduce the public project since they are projectlosers. Therefore, no majority can be formed in favor of the public project since $p^{*}$-yes votes are required under all circumstances. 
(ii) Suppose that $p \geq p^{*}$ and that an agenda-setter proposes $g=1$ and

$$
t= \begin{cases}\frac{(1+\lambda) k}{p^{*}} & \text { for a share of } p^{*} \text { individuals } \\ 0 & \text { for all others and himself }\end{cases}
$$

Denote this proposal by $\left(g=1, t=\frac{(1+\lambda) k}{p^{*}}\right)$. Since $p^{*} C_{h}+\left(1-p^{*}\right) C_{l} \geq(1+\lambda) k$ and $C_{l} \leq 0$, we have $t \leq C_{h}$. Therefore, all taxed project-winners will support the proposal. All non-taxed project-winners benefit as well and a majority of at least $p^{*}$ individuals will vote yes. Since $n_{T}=p^{*}$, the $p^{*}$-majority rule applies. Thus, the proposal will be accepted.

(iii) Project-winners and losers, however, cannot observe whether $p<p^{*}$ or $p \geq p^{*}$. By making the proposal $\left(g=1, t=\frac{(1+\lambda) k}{p^{*}}\right)$, an agenda-setter maximizes the chances of the public project being accepted without bearing taxes. In order to derive the agenda-setting costs, suppose that all agents apply for agenda-setting and propose $\left(g=1, t=\frac{(1+\lambda) k}{p^{*}}\right)$. If a project-winner can determine the agenda, his expected utility relative to the status quo, denoted by $U_{j}^{h}\left(A_{j}\right)$, is

$$
U_{j}^{h}\left(A_{j}\right)=-\operatorname{Pr}\left\{p<p^{*}\right\} b+\operatorname{Pr}\left\{p \geq p^{*}\right\} C_{h}
$$

If a project-winner cannot set the agenda, his expected utility $U_{j}^{h}\left(A_{a}\right)$ when another agenda-setter $a \neq j$ proposes $\left(g=1, t=\frac{(1+\lambda) k}{p^{*}}\right)$ is given by:

$$
U_{j}^{h}\left(A_{a}\right)=\operatorname{Pr}\left\{p \geq p^{*}\right\}\left(C_{h}-\frac{(1+\lambda) k}{p^{*}} p^{*}\right)=\operatorname{Pr}\left\{p \geq p^{*}\right\}\left(C_{h}-(1+\lambda) k\right) .
$$

For a project-loser the corresponding comparisons, if he makes the same proposal $\left(g=1, t=\frac{(1+\lambda) k}{p^{*}}\right)$, amount to:

$$
\begin{aligned}
& U_{j}^{l}\left(A_{j}\right)=-\operatorname{Pr}\left\{p<p^{*}\right\} b+\operatorname{Pr}\left\{p \geq p^{*}\right\} C_{l} \\
& U_{j}^{l}\left(A_{a}\right)=\operatorname{Pr}\left\{p \geq p^{*}\right\}\left(C_{l}-(1+\lambda) k\right)
\end{aligned}
$$

Therefore, the utility gain for both project-winners and losers when they can set the agenda and make the proposal $\left(g=1, t=\frac{(1+\lambda) k}{p^{*}}\right)$ are given by:

$$
\operatorname{Pr}\left\{p \geq p^{*}\right\}(1+\lambda) k-\operatorname{Pr}\left\{p<p^{*}\right\} b
$$

In order to motivate agenda-setting, agenda costs must therefore at least satisfy

$$
b \leq \frac{\operatorname{Pr}\left\{p \geq p^{*}\right\}(1+\lambda) k}{\operatorname{Pr}\left\{p<p^{*}\right\}}
$$

Note that agenda-setting has the same differential impact on project-winners and losers, if all others do the same and propose $\left(g=1, t=\frac{(1+\lambda) k}{p^{*}}\right)$. 
(iv) Condition (2) ensures that a project-winner is better off by applying for agendasetting when anybody else does. However, if (2) holds, project-winners are also better off applying for agenda-setting if no one else applies, since $C_{h}>k(1+\lambda)$ and thus the expected gains in this case

$$
\begin{aligned}
U_{j}^{h}\left(A_{j}\right) & =-\operatorname{Pr}\left\{p<p^{*}\right\} b+\operatorname{Pr}\left\{p \geq p^{*}\right\} C_{h} \\
& \geq \operatorname{Pr}\left\{p \geq p^{*}\right\}\left(C_{h}-k(1+\lambda)\right)
\end{aligned}
$$

are positive and hence better than the status quo. Thus, $\psi_{j}=1$ weakly dominates $\psi_{j}=0$ for project-winners. Therefore, in any equilibrium, project-winners apply for agenda-setting if (2) holds.

(v) For project-losers, the situation is more delicate. Since project-winners choose $\psi_{j}=1$, project-losers also choose $\psi_{j}=1$ if condition (2) holds. However, to deter project-losers from making unconstitutional proposals when they can set the agenda, the costs of agenda-setting must also fulfill

$$
b \geq \operatorname{Pr}\left\{p<p^{*}\right\} b+\operatorname{Pr}\left\{p \geq p^{*}\right\} C_{l}
$$

which is equivalent to $b \geq-C_{l}$. Therefore, if

$$
-C_{l} \leq b \leq \frac{\operatorname{Pr}\left\{p \geq p^{*}\right\}(1+\lambda) k}{\operatorname{Pr}\left\{p<p^{*}\right\}}
$$

all agents apply for agenda-setting and propose $g=1$ and $t=\frac{(1+\lambda) k}{p^{*}}$ for a share of $p^{*}$ individuals. If and only if $p<p^{*}$ the proposal will be rejected. Therefore $\mathrm{CO}_{4}$ implements a first-best allocation. 


\section{Proof of proposition 4:}

(i) We first consider project-winners who observe $C_{h}$. If $C_{h}<\hat{C}_{h}$, we claim that $\psi_{j}=0$ weakly dominates $\psi_{j}=1$. By the definition of $\hat{C}_{h}$ and because $C_{h}<\hat{C}_{h}$, we have $p C_{h}+(1-p) C_{l}<(1+\lambda) k$ for all $p \in[\underline{p}, \bar{p}]$. Therefore, in order to finance a project proposal $g=1$, the project-winner has two possibilities.

First, he can try to levy taxes on the whole population. In such a situation, $\bar{t}$ is equal to $k(1+\lambda)$ and $t^{\text {min }}$ cannot be higher than $k(1+\lambda)$. As $n_{T}$ is equal to the whole population, $\operatorname{DTMv}\left(p^{*}\left(t^{\mathrm{min}}\right)\left(n_{T} \leq p^{*}\left(t^{\min }\right)\right), 1\right)$ implies that the unanimity rule governs legislative decision-making. Two cases can occur. In the first case, $n_{T} \leq p^{*}\left(t^{\min }\right)$ and the $p^{*}\left(t^{\min }\right)$-majority rule will be applied; but since $n_{T}=1$, the $p^{*}\left(t^{\mathrm{min}}\right)$-majority rule implies unanimity in this case because no more than 100 percent yes-votes can be required. In the second case we have $n_{T}>p^{*}\left(t^{\mathrm{min}}\right)$ and the unanimity rule will be applied by construction of the majority rule. In both cases, project-losers will vote against the proposal and the status quo prevails.

Second, the project-winner can try to levy taxes on a fraction of the voters. As a result of the double majority rule requirement, such a proposal only has a chance of getting accepted if $t^{\mathrm{min}} \leq C_{h}$ because otherwise all taxed projectwinners would vote against $g=1$. But by definition of $\hat{C}_{h}$ and since $C_{h}<\hat{C}_{h}$, we have $p^{*}\left(t^{\min }\right)>\bar{p}$, if $t^{\text {min }} \leq C_{h}$. Since the fraction of project-winners cannot exceed $\bar{p}$, a share of yes-votes of $p^{*}\left(t^{\mathrm{min}}\right)$ cannot be achieved. According to our tie-breaking rules, project-winners will not apply for agenda-setting if $C_{h}<\hat{C}_{h}$.

(ii) Suppose that $C_{h} \geq \hat{C}_{h}$ and consider a project-winner determining the agenda. To minimize the fraction of taxed people, he can propose $g=1$ and can tax a proportion of $q=\frac{k(1+\lambda)}{C_{h}}$ individuals by a tax $t=C_{h}$. Therefore, the required majority is $p^{*}\left(t^{\mathrm{min}}\right)=p^{*}\left(C_{h}\right)$ if the share of taxed individuals $n_{T}$ is no larger than $p^{*}\left(t^{\min }\right)$. If not the unanimity rule applies.

If $p<p^{*}\left(t^{\mathrm{min}}\right)$, the proposal will be rejected since all project-losers $1-p$ will vote against a proposal $g=1$.

If $p \geq p^{*}\left(t^{\mathrm{min}}\right)$ we claim that the proposal will be accepted. Note that $p^{*}\left(t^{\min }\right)=$ $p^{*}\left(C_{h}\right)=\frac{(1+\lambda) k-C_{l}}{C_{h}-C_{l}}>\frac{(1+\lambda) k}{C_{h}}$ since $\frac{(1+\lambda) k}{C_{h}}<1$. Therefore $n_{T}<p^{*}\left(t^{\mathrm{min}}\right)$ and thus the $p^{*}\left(t^{\min }\right)$ majority rule applies. Because $t^{\text {min }}=C_{h}$, all project-winners will support the proposal and hence the double majority rule requirement is fulfilled. 
We next observe that for $C_{h} \geq \hat{C}_{h}$ applying for agenda-setting is a weakly dominant strategy for project-winners. Either $p \geq p^{*}\left(t^{\mathrm{min}}\right)$ and agenda-setting is beneficial because of the benefits from the public project and the absence of tax costs, or $p<p^{*}\left(t^{\min }\right)$ and the status quo prevails, but the costs of agenda-setting are zero since $t^{\text {min }} \geq \hat{C}_{h}$. As $t^{\text {min }} \leq C_{h}$, the share of supporting votes is at least $\underline{p}$. Thus, $\psi_{j}=1$ weakly dominates $\psi_{j}=0$ for project-winners.

(iii) Let us now consider project-losers. As a result the double majority feature of the decision rule, acceptance of a proposal $g=1$ is only achievable if $t^{\min } \leq C_{h}$ since otherwise all taxed individuals will vote against. By using the same arguments as in $(i)$, if $C_{h}<\hat{C}_{h}$ it is impossible to get $g=1$ accepted whatever financing scheme is proposed. Therefore, with probability $\operatorname{Pr}\left\{C_{h}<\hat{C}_{h}\right\}$, at least the status quo will prevail. In the next stage, we observe that the project-loser cannot avoid either the agenda costs $b_{1}$ or $b_{2}$ if $C_{h}<\hat{C}_{h}$. To avoid $b_{1}$, the agenda-setter needs to set $t^{\text {min }} \geq \hat{C}_{h}$. However, for $C_{h}<\hat{C}_{h}$ no one will support such a proposal and therefore the agenda-setter incurs $b_{2}$. If $t^{\mathrm{min}}<\hat{C}_{h}$, e.g. $t^{\mathrm{min}}=(1+k) \lambda$, the cost $b_{2}$ can be avoided, but $b_{1}$ has to be paid. Hence, expected agenda costs for project-losers are at least $\operatorname{Pr}\left\{C_{h}<\hat{C}_{h}\right\} \min \left\{b_{1}, b_{2}\right\}$. Since $b_{1}, b_{2}$ can be set at arbitrarily high levels, expected agenda costs become very large. Hence, since the maximal tax burden is limited by $\bar{C}_{h}$, not applying for agenda-setting weakly dominates agenda-setting for project-losers if $b_{1}$ and $b_{2}$ are sufficiently large.

(iv) Taking $(i),(i i)$ and (iii) together implies that $C O_{5}$ implements first-best allocations. Under $\mathrm{CO}_{5}$, there exists a unique subgame perfect equilibrium in which project-winners apply for agenda-setting if and only if $C_{h} \geq \hat{C}_{h}$. They propose $g=1 t=C_{h}$ for a share of $q=\frac{(1+\lambda) k}{C_{h}}$ individuals. The proposal is accepted if and only if $p \geq p^{*}\left(t^{\mathrm{min}}\right)$. Project-losers never apply for agenda-setting. 


\section{References}

[1] Aliprantis, C. and K. Border (2000), "Infinite Dimensional Analysis: A Hitchhikers's Guide", Springer, Heidelberg.

[2] Aghion, P. and P. Bolton (1998), "Incomplete Social Contracts", Mimeo.

[3] Al-Najjar, N.I. (1995), "Decomposition and Characterization of Risk with a Continuum of Random Variables", Econometrica, 63, 1195-1224.

[4] Alos-Ferrer, C. (1999), "Individual Randomness in Economic Models with a Continuum of Agents", Working Paper, N0. 9807, Department of Economics, University of Vienna.

[5] Austen-Smith, D. and J. Banks, (1996), "Information Aggregation, Rationality and the Condorcet Jury Theorem", American Political Science Review, 90 (1), 34-45.

[6] Berend, D. and J. Paroush, (1998), "When is the Condorcet's Jury Theorem Valid?", Social Choice and Welfare, 15, 481-488.

[7] Berg, S. (1993), "Condorcet's Jury Theorem, Dependence Among Jurers", Social Choice and Welfare, 10, 87-95.

[8] Buchanan, J.M. and G. Tullock (1965), "The Calculus of Consent: Logical Foundations of Constitutional Democracy", University of Michigan Press.

[9] Buchanan, J.M. (1998), "Majoritarian Logic", Public Choice, 97, 13-21.

[10] Caplin, A. and B. Nalebuff (1988), "On 64\%-Majority Rule", Econometrica, 56, 787-814.

[11] Dasgupta, P. and E. Maskin (1997), "Preference Domains and Majority Voting", Harvard University, Mimeo.

[12] Erlenmaier, U. and H. Gersbach (1999), "Flexible Majority Rules", Working Paper, University of Heidelberg.

[13] Feddersen, T. and W. Pesendorfer (1994), "Voting Behavior and Information Aggregation in Elections with Private Information", Econometrica, 65, 1029-1058. 
[14] Feld, L.P. and G. Kirchgässner (1998), "Die politische Ökonomie der direkten Demokratie: Eine Übersicht", Discussion Paper, No. 9807, University of St.Gallen.

[15] Feddersen, T. and W. Pesendorfer, (1996), "The Swing Voter's Curse", American Economic Review, 86, 408-424.

[16] Fudenberg, D. and J. Tirole (1992), "Game Theory", MIT Press, Cambridge, MA.

[17] Gersbach, H. (2000), "Double Majority Rules and Flexible Agenda Costs", Working Paper, www.SSRN.com

[18] Gersbach, H., Haller, H. (2001), "Collective Decisions and Competitive Markets", Review of Economic Studies, 68, 347-368.

[19] Harsanyi, J.(1955), "Cardinal Welfare, Individual Ethics and Interpersonal Comparability of Utility", Journal of Political Economy, 61, 309-321.

[20] Ladha, K.K. (1992), "The Condorcet Jury Theorem, Free Speech and Correlated Votes", American Journal of Political Science, 36, 617-634.

[21] Laffont, J.-J. (1995), "Industrial Policy and Politics", International Journal of Industry Organization, 14, 1-27.

[22] May, K.O. (1954), "A set of independent, necessary and sufficient conditions for simple majority decisions", Econometrica, 20 (4), 680-684.

[23] Mirrless, J. (1971), "An Exploration in the Theory of Optimum Income Taxation", Review of Economic Studies, 38, 175-208.

[24] Moore, J. (1992), "Implementation, contracts, and renegotiation in environments with complete information", in Advances in Economic Theory, ed. by J.-J. Laffont, Cambridge University Press, Cambridge,MA, 1, 182-282.

[25] Moulin, H. (1996), "Strategy Proofness: News from the Front". Paper presented at the third International Meeting of the Society for Social Choice and Welfare, Maastricht.

[26] Myerson, R. (1994), "Extended Poisson Games and the Condorcet Jury Theorem", Mimeo, Northwestern University. 
[27] Piketty, T. (1999), "The Information Aggregation Approach to Political Institutions", European Economic Review, 43, 791-800.

[28] Piketty, T. (2000), "Voting as Communication", Review of Economic Studies, 67, 169-191.

[29] Rae, D. (1969), "Decision Rules and Individual Values in Constitutional Choice", American Science Review, 63, 40-56.

[30] Rawls, J. (1971), "A Theory of Justice", Cambridge, Belknap.

[31] Romer, T. and H. Rosenthal (1983), "A Constitution for Solving Asymmetric Externality Games", American Journal of Political Science, 27, 1-26.

[32] Saunders, C. (2001), "The Parliament as Partner: A Century of Constitutional Review", University of Melbourne Law School, Public Law Research Paper No. 12.

[33] Taylor, M.J. (1969), "Proof of a Theorem on Majority Rule", Behavioral Science, $14,228-231$.

[34] Voigt, S. (1998), "Constitutional Law", in Boudewijn Bouckaert and Gerrit de Geest (eds.) Encyclopedia of Law \& Economics, Edward Elgar.

[35] Walker, C. and Y. Akdeniz (1997), "Virtual Democracy", presented at the JETAI Conference, University of Glasgow, November 1997.

[36] Wicksell, K. (1896), "A Principle of Just Taxation", reprinted in Classics in the Theory of Public Finance, New York, St. Martin's Press, 72-118.

[37] Uhlig, H. (1996), "A Law of Large Numbers for Large Economies", reprinted in Economic Theory, 8, 41-50. 


\section{CESifo Working Paper Series}

683 Jörg Baten, Did Partial Globalization Increase Inequality? Did Inequality Stimulate Globalization Backlash? The case of the Latin American Periphery, 1950-80, March 2002

684 Norman Loayza and Romain Ranciere, Financial Development, Financial Fragility, and Growth, March 2002

685 Thomas Eichner and Andreas Wagener, Increases in Risk and the Welfare State, March 2002

686 Hyun Park and Apostolis Philippopoulos, Can Poductive Government Spending be the Engine of Long-Run Growth When Labor Supply is Engogenous?, March 2002

687 Jonathan P. Thomas and Tim Worrall, Gift-Giving, Quasi-Credit and Reciprocity, March 2002

688 Barbara Buchner, Carlo Carraro, Igor Cersosimo, and Carmen Marchiori, Back to Kyoto? US Participation and the Linkage between R\&D and Climate Cooperation, March 2002

689 Amihai Glazer and Vesa Kanniainen, The Effects of Employment Protection on the Choice of Risky Projects, March 2002

690 Michael Funke and Annekatrin Niebuhr, Threshold Effects and Regional Economic Growth - Evidence from West Germany, March 2002

691 George Economides, Apostolis Philippopoulos, and Simon Price, Elections, Fiscal Policy and Growth: Revisiting the Mechanism, March 2002

692 Amihai Glazer, Vesa Kanniainen, and Mikko Mustonen, Innovation of Network Goods: A Non-Innovating Firm Will Gain, March 2002

693 Helmuth Cremer, Jean-Marie Lozachmeur, and Pierre Pestieau, Social Security, Retirement Age and Optimal Income Taxation, April 2002

694 Rafael Lalive and Josef Zweimüller, Benefit Entitlement and the Labor Market: Evidence from a Large-Scale Policy Change, April 2002

695 Hans Gersbach, Financial Intermediation and the Creation of Macroeconomic Risks, April 2002

696 James M. Malcomson, James W. Maw, and Barry McCormick, General Training by Firms, Apprentice Contracts, and Public Policy, April 2002

697 Simon Gächter and Arno Riedl, Moral Property Rights in Bargaining, April 2002 
698 Kai A. Konrad, Investment in the Absence of Property Rights: The Role of Incumbency Advantages, April 2002

699 Campbell Leith and Jim Malley, Estimated General Equilibrium Models for the Evaluation of Monetary Policy in the US and Europe, April 2002

700 Yin-Wong Cheung and Jude Yuen, Effects of U.S. Inflation on Hong Kong and Singapore, April 2002

701 Henry Tulkens, On Cooperation in Musgravian Models of Externalities within a Federation, April 2002

702 Ralph Chami and Gregory D. Hess, For Better or For Worse? State-Level Marital Formation and Risk Sharing, April 2002

703 Fredrik Andersson and Kai A. Konrad, Human Capital Investment and Globalization in Extortionary States, April 2002

704 Antonis Adam and Thomas Moutos, The Political Economy of EU Enlargement: Or, Why Japan is not a Candidate Country?, April 2002

705 Daniel Gros and Carsten Hefeker, Common Monetary Policy with Asymmetric Shocks, April 2002

706 Dirk Kiesewetter and Rainer Niemann, Neutral and Equitable Taxation of Pensions as Capital Income, April 2002

707 Robert S. Chirinko, Corporate Taxation, Capital Formation, and the Substitution Elasticity between Labor and Capital, April 2002

708 Frode Meland and Gaute Torsvik, Structural Adjustment and Endogenous Worker Recall Probabilities, April 2002

709 Rainer Niemann and Caren Sureth, Taxation under Uncertainty - Problems of Dynamic Programming and Contingent Claims Analysis in Real Option Theory, April 2002

710 Thomas Moutos and William Scarth, Technical Change and Unemployment: Policy Responses and Distributional Considerations, April 2002

711 Günther Rehme, (Re-)Distribution of Personal Incomes, Education and Economic Performance Across Countries, April 2002

712 Thorvaldur Gylfason and Gylfi Zoega, Inequality and Economic Growth: Do Natural Resources Matter?, April 2002

713 Wolfgang Leininger, Contests over Public Goods: Evolutionary Stability and the FreeRider Problem, April 2002

714 Ernst Fehr and Armin Falk, Psychological Foundations of Incentives, April 2002 
715 Giorgio Brunello, Maria Laura Parisi, and Daniela Sonedda, Labor Taxes and Wages: Evidence from Italy, May 2002

716 Marta Aloi and Huw Dixon, Entry Dynamics, Capacity Utilisation and Productivity in a Dynamic Open Economy, May 2002

717 Paolo M. Panteghini, Asymmetric Taxation under Incremental and Sequential Investment, May 2002

718 Ben J. Heijdra, Christian Keuschnigg, and Wilhelm Kohler, Eastern Enlargement of the EU: Jobs, Investment and Welfare in Present Member Countries, May 2002

719 Tapio Palokangas, The Political Economy of Collective Bargaining, May 2002

720 Gilles Saint-Paul, Some Evolutionary Foundations for Price Level Rigidity, May 2002

721 Giorgio Brunello and Daniela Sonedda, Labor Tax Progressivity, Wage Determination, and the Relative Wage Effect, May 2002

722 Eric van Damme, The Dutch UMTS-Auction, May 2002

723 Paolo M. Panteghini, Endogenous Timing and the Taxation of Discrete Investment Choices, May 2002

724 Achim Wambach, Collusion in Beauty Contests, May 2002

725 Dominique Demougin and Claude Fluet, Preponderance of Evidence, May 2002

726 Gilles Saint-Paul, Growth Effects of Non Proprietary Innovation, May 2002

727 Subir Bose, Gerhard O. Orosel, and Lise Vesterlund, Optimal Pricing and Endogenous Herding, May 2002

728 Erik Leertouwer and Jakob de Haan, How to Use Indicators for 'Corporatism' in Empirical Applications, May 2002

729 Matthias Wrede, Small States, Large Unitary States and Federations, May 2002

730 Christian Schultz, Transparency and Tacit Collusion in a Differentiated Market, May 2002

731 Volker Grossmann, Income Inequality, Voting Over the Size of Public Consumption, and Growth, May 2002

732 Yu-Fu Chen and Michael Funke, Working Time and Employment under Uncertainty, May 2002

733 Kjell Erik Lommerud, Odd Rune Straume, and Lars Sørgard, Downstream Merger with Oligopolistic Input Suppliers, May 2002 
734 Saku Aura, Does the Balance of Power Within a Family Matter? The Case of the Retirement Equity Act, May 2002

735 Sandro Brusco and Fausto Panunzi, Reallocation of Corporate Resources and Managerial Incentives in Internal Capital Markets, May 2002

736 Stefan Napel and Mika Widgrén, Strategic Power Revisited, May 2002

737 Martin W. Cripps, Godfrey Keller, and Sven Rady, Strategic Experimentation: The Case of Poisson Bandits, May 2002

738 Pierre André Chiappori and Bernard Salanié, Testing Contract Theory: A Survey of Some Recent Work, June 2002

739 Robert J. Gary-Bobo and Sophie Larribeau, A Structural Econometric Model of Price Discrimination in the Mortgage Lending Industry, June 2002

740 Laurent Linnemer, When Backward Integration by a Dominant Firm Improves Welfare, June 2002

741 Gebhard Kirchgässner and Friedrich Schneider, On the Political Economy of Environmental Policy, June 2002

742 Christian Keuschnigg and Soren Bo Nielsen, Start-ups, Venture Capitalits, and the Capital Gains Tax, June 2002

743 Robert Fenge, Silke Uebelmesser, and Martin Werding, Second-best Properties of Implicit Social Security Taxes: Theory and Evidence, June 2002

744 Wendell Fleming and Jerome Stein, Stochastic Optimal Control, International Finance and Debt, June 2002

745 Gene M. Grossman, The Distribution of Talent and the Pattern and Consequences of International Trade, June 2002

746 Oleksiy Ivaschenko, Growth and Inequality: Evidence from Transitional Economies, June 2002

747 Burkhard Heer, Should Unemployment Benefits be Related to Previous Earnings?, July 2002

748 Bas van Aarle, Giovanni Di Bartolomeo, Jacob Engwerda, and Joseph Plasmans, Staying Together or Breaking Apart: Policy-makers' Endogenous Coalitions Formation in the European Economic and Monetary Union, July 2002

749 Hans Gersbach, Democratic Mechanisms: Double Majority Rules and Flexible Agenda Costs, July 2002 